\title{
Ocultamento do auxílio? Programa de Volta Para Casa em documentos e eventos
}

\author{
Concealment of financial aid? The Volta para Casa (Back Home) \\ Program on documents and events
}

Milene Santiago Nascimento (https://orcid.org/0000-0002-5132-1723) ${ }^{1}$

Martinho Braga Batista e Silva (https://orcid.org/0000-0003-3577-958X) ${ }^{1}$
${ }^{1}$ Instituto de Medicina Social, Universidade do Estado do Rio de Janeiro. São Francisco Xavier 524 Bloco D e E, R 7o andar, Maracanã. 20550-900 Rio de Janeiro RJ Brasil. milenesantiago@ hotmail.com

\begin{abstract}
A fundamental government initiative to change the living conditions of deinstitutionalized Brazilian people, the De Volta para Casa (Back Home) Program is formed by some elements, including the psychosocial rehabilitation financial aid. Thirty-four state and academic documents from ordinances to papers were gathered to identify which elements of the Program permeate the records and debates about it throughout the Brazilian Psychiatric Reform, converging with the studies of Juarez Pereira Furtado and Ligia Maria Vieira-da-Silva about the dynamics of scientific and bureaucratic fields, such as mental health. Furthermore, we ethnographed five events that gathered institutionalized people and other agents from this field. We noticed the remarkable presence of the Therapeutic Residential Services (SRT) as an element of the referred Program both in the records and the scientific debates, while the mentioned financial aid was highlighted mainly in the government records.
\end{abstract}

Key words Ethnography, Mental health, De Volta Para Casa, Deinstitutionalization
Resumo O Programa de Volta para Casa, iniciativa governamental fundamental para modificar as condições de vida de egressos de internação psiquiátrica no Brasil, é formado por alguns componentes, entre eles o auxílio-reabilitação psicossocial. Com o objetivo de identificar quais componentes do referido Programa estão presentes nos registros e debates sobre ele ao longo do processo de Reforma Psiquiátrica Brasileira, 34 documentos foram reunidos, de portarias a artigos, em convergência com os estudos de Juarez Pereira Furtado e Ligia Maria Vieira-da-Silva sobre a dinâmica de campos ao mesmo tempo científicos e burocráticos, como o da saúde mental. Além disso, cinco eventos que reuniam egressos de internação psiquiátrica e outros agentes desse campo foram etnografados. Notamos a presença marcante do Serviço Residencial Terapêutico como componente do referido Programa nos registros e debates científicos, enquanto o mencionado auxílio foi destacado principalmente nos registros governamentais. Palavras-chave Etnografia, Saúde mental, Programa de Volta Para Casa, Desinstitucionalização 


\section{Introdução}

Uma das dimensões do processo de reforma psiquiátrica brasileira é a jurídico-política ${ }^{1}$, expressa em pelo menos duas conquistas legislativas: a Lei 10.216/2001, conhecida como lei antimanicomial, que redireciona o modelo assistencial em saúde mental e diz respeito aos direitos das pessoas com transtorno mental; e a Lei 10.708/2003, que se refere ao Programa de Volta para Casa (PVC) e institui o auxílio-reabilitação psicossocial, um benefício destinado aos pacientes egressos de internações psiquiátricas. A construção dessas leis envolveu um conjunto de eventos públicos, entre eles sessões e audiências no Congresso Nacional, e decorreram de outros documentos governamentais, tais como projetos de lei. Esse processo contou com usuários, familiares e mais integrantes do campo da saúde mental no processo de aprovação dos ditos "substitutivos" mentos nos quais o PVC é mencionado e eventos nos quais ele é discutido nos ajudarão a compreendê-lo nas páginas que se seguem. Propomos voltar a atenção para os registros e debates em torno dessa iniciativa destinada a inclusão social de egressos de internação psiquiátrica, segmento populacional do qual fazem parte muitos protagonistas da luta antimanicomial ${ }^{3}$.

Além da dimensão jurídico-política, o processo de reforma psiquiátrica brasileira também é composto de uma dimensão técnico-assistencial, outra teórico-conceitual e ainda a sociocultural, de maneira que sua complexidade inclui o aumento da oferta de serviços extra-hospitalares de saúde mental, mas não se limita a ele ${ }^{4}$. Para que efetivamente possamos alterar a visão que a maioria das pessoas tem sobre os ditos "problemas mentais", precisamos sacudir formas de pensar, sentir e agir sedimentadas ao longo de décadas, gerações e mesmo séculos, como as expectativas que costumamos nutrir em relação ao comportamento dos ex-pacientes de hospitais psiquiátricos. Sabemos que muitos deles geralmente são vistos como potencialmente incapazes e incuráveis, quando não perigosos e irresponsáveis, bem como que os beneficiários do PVC colocam em xeque esse estatuto social da loucura ${ }^{5}$. Experiências em diferentes regiões do Brasil mostram que eles gerenciam total ou parcialmente seus bens e mantêm seus sintomas psicopatológicos estáveis durante intervalos de tempo que chegam a superar o período que ficaram internados $s^{6,7}$.

Um dos registros que investigaremos é a mencionada lei que institui o auxílio-reabilitação psicossocial, documento governamental no qual é informado que o benefício é parte integrante do PVC, e que ele consiste em um pagamento mensal de auxílio pecuniário destinado aos pacientes egressos de internações ${ }^{9}$, de maneira que o designaremos a partir de agora como auxílio. Mais um registro que também é um documento governamental é o manual do PVC, no qual o auxílio é apresentando como seu principal componente, sendo que esta estratégia governamental para estimular a assistência extra-hospitalar também é composta de Serviços Residenciais Terapêuticos (SRTs) e Centros de Atenção Psicossociais (CAPS $)^{10}$. Outros registros sobre o PVC são os documentos científicos, sendo que alguns estudos sobre o PVC podem chegar a abordar exclusivamente os SRTs, sem sequer mencionar o auxílio como um de seus componentes. ${ }^{8}$ Os demais artigos científicos sobre o PVC mencionam o auxílio em composição com outros benefícios, como o Benefício de Prestação Continuada $(\mathrm{BPC})^{6}$ e há ainda os que apontam problemas jurídicos na administração destes benefícios em SRTs, dificultando a expansão do PVC em alguns municípios e estados da federação ${ }^{11}$. A mudança no lugar social da loucura é notável quando egressos de internação psiquiátrica deixam de ser considerados dependentes no seio familiar e passam a sê-lo provedores ${ }^{6}$, embora esse papel social generificado também demande problematização no campo da saúde mental ${ }^{7}$.

O campo da saúde mental é ao mesmo tempo científico, político e burocrático ${ }^{12}$, semelhante ao campo da saúde coletiva, neste sentido ${ }^{13}$. Sendo assim, seus agentes circulam pela academia, o serviço e a militância. Trabalhadores e também usuários atuam em diferentes níveis de gestão e setores do Poder Executivo. Familiares e outros porta-vozes representam o campo da saúde mental, inclusive no Poder Legislativo Federal, sem falar nos projetos de pesquisa e extensão articulados ao movimento social desenvolvidos por professores em muitas universidades. Além das leis e manuais citados anteriormente, portarias do Ministério da Saúde e uma série de outros documentos condensam o ponto de vista sobre o PVC desses agentes do campo da saúde mental, designados "mentaleiros". Muitos desses documentos governamentais são discutidos em congressos científicos, não somente em sessões e audiências do Congresso Nacional. Deste modo, documentos e eventos permeiam o referido campo, registros e debates ora visibilizando ora ocultando os componentes do PVC, tais como o auxílio e o SRT. 
Nosso objetivo é identificar quais componentes do PVC estão presentes nos registros e debates sobre ele ao longo do processo de Reforma Psiquiátrica Brasileira, por meio da consulta a documentos do governo federal em que o PVC é mencionado, a artigos científicos sobre o PVC e debates sobre o mesmo em eventos do campo da saúde mental.

\section{Referencial teórico-metodológico}

Este estudo sobre o PVC envolve análise documental e etnografia de eventos: a primeira com base em uma pesquisa nacional sobre inserção social de egressos de internação psiquiátrica, que se desdobrou em uma análise documental sobre a concepção de território no campo da saúde mental ${ }^{12}$; e a segunda com base em etnografias de congressos científicos de psiquiatria ${ }^{14}$ e a chamada "etnografia de interface"15. As duas metodologias possibilitam compreender o modo através do qual o PVC é apreendido no referido campo, as categorias de percepção e a apreciação da realidade que seus agentes registram em documentos governamentais e científicos e também aquelas que eles pronunciam em debates públicos ${ }^{13}$.

Adotamos os mesmos procedimentos metodológicos que Furtado et al. ${ }^{12}$ para reunir documentos: consulta tanto de portarias e outras normativas do governo federal quanto de artigos disponíveis em bases de dados científicas. Deste modo, também reunimos documentos governamentais por meio da consulta à página da Coordenação de Saúde Mental do Ministério da Saúde e da Biblioteca Virtual de Saúde (BVS) e artigos científicos em periódicos indexados na base Scielo. A nossa busca foi realizada em 2019 e utilizou os seguintes descritores: "Programa de Volta para Casa" (and) "saúde mental"; "Programa de Volta para Casa" (and) "desinstitucionalização"; "Programa de Volta para Casa” (and) "Serviço Residencial Terapêutico"; "auxílio reabilitação” (and) "saúde mental”; “auxílio reabilitação" (and) "Serviço Residencial Terapêutico"; e "auxílio reabilitação" (and) “desinstitucionalização". O período de busca de documentos oficiais de Furtado et al. ${ }^{12}$ foi de 1992 a 2015 e de artigos científicos de 2005 até 2015, ampliamos o último até o ano de 2019 e o primeiro até 1990, tomando o conceito de desinstitucionalização ${ }^{5}$ como marco histórico para investigação. Apenas publicações em língua portuguesa com texto completo foram incluídas, sendo que não chegamos a consultar as bases LILACS, Scopus e PubMed.
A análise dos documentos permitiu que Furtado et al. ${ }^{12}$ distinguissem quatro acepções de território: a) como área de cobertura e ação de serviços extra-hospitalares; b) como conjunto de recursos terapêuticos; c) como história pessoal de cada indivíduo; d) como sistema de objetos e ações. As duas primeiras acepções constituem o chamado polo de dominância funcional, propícias à dominação político mais concreta, e os dois últimos o polo de dominância simbólica, propícias às apropriações subjetivas e culturais. No nosso caso, isolamos dois componentes do PVC: o auxílio e o SRT. Os documentos governamentais e científicos acentuam ambos ou apenas um desses elementos. Além disso, consideramos que quando o PVC se reduz ao processo de saída do hospital psiquiátrico e à necessária implantação de serviços substitutivos ele se encontra próximo do polo dominância funcional. $\mathrm{O}$ polo de dominância simbólica se faz presente quando os componentes são colocados como dispositivos estratégicos para a desmontagem do pressuposto de incapacidade e cronicidade dos egressos de internação psiquiátrica.

Além da análise documental da produção científica e estatal sobre o PVC, conduzimos uma etnografia de interface ${ }^{15}$ em eventos do campo da saúde mental, espaço familiar aos autores deste manuscrito e frequentadores destas atividades na condição de trabalhadores. Ortner ${ }^{15}$ considera este tipo de etnografia uma forma de realizar observação participante em eventos públicos, focalizada nas falas pronunciadas. Indica que os eventos se situam em um "entre", onde as pessoas se apresentam e relatam suas experiências, permanecendo essas falas em domínio público. Nesse sentido, presenciar debates sobre o PVC em eventos foi um modo acessar os pronunciamentos públicos sobre os egressos de internação psiquiátrica e também deles próprios. Nestas situações, termos que são próprios do campo da saúde mental - desinstitucionalização, por exemplo - são compartilhados externamente, já que nestes espaços é permitida a presença de agentes que não necessariamente pertencem ao mesmo.

$\mathrm{Na}$ etnografia de um evento da Associação Brasileira de Psiquiatria realizada por Azize ${ }^{14}$, os estandes e o marketing relacionado aos psicofármacos ganharam relevo. Na nossa etnografia em eventos de saúde mental, foram as apresentações de trabalhos científicos e as mesas redondas que se destacaram. Selecionamos eventos promovidos por associações e outras instituições, levando em conta a presença de debates sobre desinstitucionalização no título, nos eixos temáticos e/ou 
programação de atividades. Adotamos os mesmos procedimentos de Azize ${ }^{14}$ : preparação para a atividade (estudo teórico e encontro prévio com alguns agentes do campo), apresentação das características do evento e de seus participantes (com recorte de idade, gênero e formação).

Ao ouvir os debates, percebemos algo que não se fez presente nos registros em documentos, de maneira que os eventos constituíram como um espaço fecundo para alcançarmos as diferentes perspectivas que o PVC adquire para os ditos "mentaleiros". A observação participante dos eventos aconteceu entre os anos de 2018 e 2019 e o projeto de pesquisa foi submetido ao Comitê de Ética e Pesquisa, sendo autorizada pelo parecer número 3.386.261.

\section{Resultados e discussão}

A análise documental do campo da saúde mental reuniu 34 documentos, 29 deles governamentais e cinco científicos. A etnografia de eventos envolveu a observação participante de cinco eventos desse campo burocrático e científico. Apresentaremos, a seguir, esses registros e debates sobre o PVC, acompanhados de análises sobre o que é visibilizado e ocultado nesses espaços sociais de circulação de agentes em disputa, particularmente pelo poder de determinar o que deve ser financiado pelo poder público e estudado pelos pesquisadores em saúde mental.

\section{Documentos governamentais}

Os 29 documentos (Quadro 1) incluem portarias, recomendações, resoluções, relatórios de gestão e de conferências de saúde mental, entre eles a citada lei e manual ${ }^{9,10}$.

O PVC retratado nestas normativas inclui ações de cuidado no território, viabilização de habitação e outras atividades que remetem ao polo de dominância funcional ${ }^{12}$. Além disso, o que é mais enfatizado nestes documentos oficiais é o pagamento de um auxílio para egressos de internações psiquiátricas. O auxílio pode ser destinado tanto aos moradores dos SRTs, quanto para aqueles que retornaram para as residências familiares, ou mesmo para suas próprias moradias. Ou seja, nesses registros o PVC necessariamente está atrelado ao auxílio, embora não necessariamente aos SRTs.

O PVC atende à Lei no 10.2016/2001, envolvendo assim ações de inclusão social, exercício de direitos e autonomia ${ }^{16}$. As ações previstas pelo
PVC podem ser consideradas estratégicas para o processo de desinstitucionalização, sendo que destacamos o seguinte comentário sobre a Lei ${ }^{\circ}$ 10.708/2003 ${ }^{17}$ :

Lei do Programa De Volta Para Casa. Estabelece um novo patamar na história do processo de reforma psiquiátrica brasileira, impulsionando a desinstitucionalização de pacientes com longo tempo de permanência em hospital psiquiátrico, pela concessão de auxílio reabilitação psicossocial e inclusão em programas extra-hospitalares de atenção em saúde mental ${ }^{17}$. (p. 25)

Além da lei e do manual que colaboraram para constituir o marco histórico de nossa investigação, verificamos outros três documentos que orientam o PVC: a) "Residências Terapêuticas: o que são e para que servem?", manual sobre os SRTs, de 2004; b) Portaria no 3.088, de 2011, que define o PVC e os SRTs como estratégia de desinstitucionalização, componente da Rede de Atenção Psicossocial (RAPS); c) e Portaria 2.840/2014, que institui o Programa de Desinstitucionalização, preconizando ações para acesso aos benefícios financeiros, como uma das atribuições da equipe de desinstitucionalização. Estes documentos têm em comum diretrizes que orientam sobre o PVC, ou seja, sua definição, objetivos, critérios de inserção de usuários no programa, bem como sua implantação. Além disso, o PVC é mencionado ao lado de "desinstitucionalização", confirmando que o primeiro é peça importante para a segunda.

Ao considerarmos que a desinstitucionalização é polissêmica ${ }^{18}$, podemos atribuir diferentes sentidos a ela. Dentre eles, um conjunto de estratégias que viabilizam a alta hospitalar, a reinserção social, resgate do poder de contratualidade social e cuidado no território. Estas estratégias vão desde ações administrativas (fechamentos de hospitais psiquiátricos, redução de leitos, financiamento de rede de cuidados territoriais) a mudanças no modelo de assistência, envolvendo SRTs e o PVC. Assim, entendendo que os documentos governamentais versam sobre as orientações e diretrizes do PVC, somado ao fato de que esses mesmos documentos integram o PVC às estratégias de desinstitucionalização, podemos afirmar que desinstitucionalização e PVC não podem ser cindidos.

Verificamos também outros documentos governamentais que determinam a adesão dos municípios ao PVC, sendo esta a condição para o desenvolvimento de ações e até mesmo para o recebimento de verbas específicas. São eles: a Portaria GM/MS no52/2004, que institui o Pro- 
Quadro 1. Documentos governamentais que mencionam o PVC.

\begin{tabular}{|c|c|c|c|}
\hline & Tipo de documento & Título do documento & Ano \\
\hline 01 & Lei & Lei n 10.708 & 2003 \\
\hline 02 & Portaria & Port. GM/MS n 2.077 & 2003 \\
\hline 03 & Portaria & Port. GM/MS no 2.078 & 2003 \\
\hline 04 & Publicação Oficial & Recomendação no 008 , de 08/05/2003, do Conselho Nacional de Saúde & 2003 \\
\hline 05 & Publicação Oficial & Manual do Programa De Volta para Casa & 2003 \\
\hline 06 & Portaria & Port. GM/MS n 52 & 2004 \\
\hline 07 & Portaria & Port. GM/MS nº 595 & 2004 \\
\hline 08 & Portaria & Port. GM/MS nº 2.068 & 2004 \\
\hline 09 & Portaria & Port. GM/MS no 2.069 & 2004 \\
\hline 10 & Publicação Oficial & Residências Terapêuticas: o que são e para que servem & 2004 \\
\hline 11 & Publicação Oficial & $\begin{array}{l}\text { Resolução no 3, de 04/05/2004, do Conselho Nacional de Política } \\
\text { Criminal e Penitenciária e Conselho Nacional de Justiça }\end{array}$ & 2004 \\
\hline 12 & Portaria & Port. GM/MS n 246 & 2005 \\
\hline 13 & Portaria & Port. GM/MS no 1.169 & 2005 \\
\hline 14 & Publicação Oficial & $\begin{array}{l}\text { Reforma Psiquiátrica e Política de Saúde Mental no Brasil - Conferência } \\
\text { Regional de Reforma dos Serviços de Saúde Mental: } 15 \text { anos depois de } \\
\text { Caracas }\end{array}$ & 2005 \\
\hline 15 & Publicação Oficial & Saúde mental e economia solidária: inclusão social pelo trabalho & 2005 \\
\hline 16 & Portaria & Port. GM/MS nº 678 & 2006 \\
\hline 17 & Publicação Oficial & $\begin{array}{l}\text { Saúde mental no SUS: acesso ao tratamento e mudança do modelo de } \\
\text { atenção. Relatório de Gestão 2003-2006 }\end{array}$ & 2007 \\
\hline 18 & Publicação Oficial & Saúde Mental em dados - Ano II - no 04 & 2007 \\
\hline 19 & Publicação Oficial & Saúde Mental em dados - Ano III - nº 05 & 2008 \\
\hline 20 & Publicação Oficial & Mostra fotográfica Programa de Volta para Casa - cartilha de monitoria & 2008 \\
\hline 21 & Publicação Oficial & Saúde Mental em dados - Ano IV - no 06 & 2009 \\
\hline 22 & $\begin{array}{l}\text { Relatório de } \\
\text { Conferência Nacional } \\
\text { de Saúde Mental }\end{array}$ & IV Conferência Nacional de Saúde Mental: relatório final & 2010 \\
\hline 23 & Publicação Oficial & $\begin{array}{l}\text { Saúde mental no SUS: as novas fronteiras da Reforma Psiquiátrica. } \\
\text { Relatório de Gestão: 2007-2010 }\end{array}$ & 2011 \\
\hline 24 & Publicação Oficial & Saúde Mental em dados - Ano VI - nº 08 & 2011 \\
\hline 25 & Portaria & Port. MS no 3.088 & 2011 \\
\hline 26 & Publicação Oficial & Saúde Mental em dados - Ano VII - nº 10 & 2012 \\
\hline 27 & Publicação Oficial & Saúde Mental em dados - Ano VII - no 11 & 2012 \\
\hline 28 & Portaria & Port. nº 2.840 & 2014 \\
\hline 29 & Publicação Oficial & Saúde Mental em dados - Ano X - no 12 & 2015 \\
\hline
\end{tabular}

Fonte: Biblioteca Virtual de Saúde; Página da Coordenação de Saúde Mental no Ministério da Saúde.

grama Anual de Reestruturação da Assistência Psiquiátrica; "Saúde mental e economia solidária: inclusão social pelo trabalho" (2005), que afirma o PVC como um projeto de inclusão social; a Portaria GM no 1.169/2005 e no 678/2006, relativa aos programas de supervisão; e Portaria MS no 3.088/2011, sobre o incentivo financeiro para implantação e custeio dos SRT. Todos esses documentos acentuam o polo de dominância funcional ${ }^{12}$.

Sobre o polo de dominância simbólica ${ }^{12}$, relativo à desconstrução das ideias de incapacidade e cronicidade, seria bem ilustrado pela "Mostra fotográfica Programa de Volta para Casa"19. Ela faz um recorte geográfico na história da saúde mental no Brasil e enfatiza o papel do auxílio para a vida dos beneficiários. O documento traz dois aspectos fundamentais do PVC, ou seja, enfatiza seu lugar no tripé que é alicerce para a desinstitucionalização e seu aspecto indenizatório:

Em conjunto com o Programa de Redução de Leitos Hospitalares de Longa Permanência e os Serviços Residenciais Terapêuticos, o 'Programa De Volta para Casa' forma o tripé essencial para o efe- 
tivo processo de desinstitucionalização e resgate da cidadania das pessoas acometidas por transtornos mentais submetidas à privação da liberdade nos hospitais psiquiátricos brasileiros ${ }^{19}$ (p. 15. Grifo do autor)

O auxílio-reabilitação psicossocial, instituído pelo Programa De Volta para Casa, também tem um caráter indenizatório àqueles que, por falta de alternativas, foram submetidos a tratamentos aviltantes e privados de seus direitos básicos de cidadania ${ }^{19}$. (p. 15. Grifo do autor)

O relatório da última Conferência Nacional de Saúde Mental, evento público do campo burocrático da saúde mental realizado há uma década, também destaca essa articulação entre PVC e desinstitucionalização. $\mathrm{O}$ documento atrela o PVC mais aos SRTs do que ao auxílio. Em seu sumário constam três eixos, e no segundo eixo, apresenta um item intitulado "Desinstitucionalização, inclusão e proteção social: Residências Terapêuticas, Programa de Volta para Casa e articulação intersetorial no território"20. Nenhuma das 31 propostas apresentadas neste item aborda explicitamente o auxílio. Apenas tangencialmente, o item menciona os "benefícios", ou seja, o auxílio, no trecho sobre "acessibilidade"20 (p. 83). Enquanto isso, todos os trechos apresentam sugestões de ampliação e alteração dos SRTs, desde o item "princípios e diretrizes gerais" até o item "financiamento".

A série de documentos oficiais designada Saúde Mental em Dados inclui o PVC ora no interior do item "Estratégias de desinstitucionalização" (a partir de 2012, ou seja, de seu número oito a doze) ora no item Rede de Atenção Psicossocial (antes da data mencionada). Nos dois casos apresenta o número de beneficiários do Programa, sem destacar o auxílio. Além disso, no primeiro caso, o primeiro subitem é sobre o número de SRTs, não de auxílios. Já no segundo caso, o lugar do PVC como indicador do Pacto pela Vida é realçado.

Esta farta produção burocrática sobre o PVC indica uma diversidade de ações que estão condicionadas pela adesão dos municípios ao mesmo. A produção científica sobre o PVC estaria em convergência com o que foi encontrado no documento da nossa última Conferência Nacional de Saúde Mental?

\section{Publicações científicas}

Vastas são as publicações científicas no campo da saúde mental, entre elas estudos de caso, revisões bibliográficas, resultados de pesquisas quantitativas e qualitativas e relatos de experiência. Notamos uma relação entre os relatos de experiência e documentos governamentais no campo da saúde mental, remetendo ao fato do mesmo ser ao mesmo tempo científico e burocrático ${ }^{12}$. Entendemos que os documentos governamentais são construídos com base em achados científicos, de acordo com as necessidades encontradas nas práticas dos trabalhadores, visando regulá-las, financiá-las e impulsioná-las. As publicações governamentais podem induzir as publicações científicas, e vice-versa.

Partindo destas inferências, realizamos nossa investigação nos documentos científicos. Encontramos cinco artigos.

Antes de passarmos a outras análises, gostaríamos de destacar um achado importante. Os documentos indicados no Quadro 2 pelos números 3, 4 e 5 são recortes de uma mesma pesquisa, que envolveu estudiosos de diversas instituições públicas brasileiras. Este estudo e o indicado pelo número 1 no Quadro 2, referem que, em investigação bibliográfica sobre o PVC, encontraram dado semelhante aos nossos resultados: o número diminuto de trabalhos. As quatro pesquisas, diferentemente de nós, que nos centramos somente em artigos, também se debruçaram em teses, dissertações e capítulos de livro. Ao total, são cinco dissertações, uma tese e um capítulo de livro. Os artigos identificados pelos trabalhos 3 , 4 e 5 são os mesmos que encontramos, ou seja, o 1 e 2 .

Com estes dados, verificamos que temos poucas pesquisas e trabalhos publicados sobre o PVC, sobretudo se compararmos ao número de publicações a respeito dos SRTs e desinstitucionalização. Duas hipóteses podem justificar esse cenário: 1) número reduzido de experiências com o PVC, sobretudo com o auxílio, ou ainda, a não publicização destas experiências; 2) existência de uma cisão entre o auxílio e a desinstitucionalização como desconstrução da lógica manicomial $^{5}$. O PVC permaneceria apenas como uma ação administrativa, isto é, inserção de usuários como etapa para credenciamento de serviços e recebimento de verba. O auxílio remeteria ao uso do benefício para necessidades gerais, como por exemplo pequenas reformas nos SRTs e compra de materiais básicos.

Lima e Brasil ${ }^{21}$ apontam que as possíveis causas do número reduzido de trabalhos estariam relacionadas a pouca importância despendida ao programa pelos profissionais e que os mesmos não conseguem entendê-lo como um operador da desinstitucionalização. Estas reflexões coin- 
Quadro 2. Artigos científicos que tratam do Programa de Volta para Casa.

\begin{tabular}{|c|c|c|c|c|}
\hline & Título & Autor (res) & Ano & Revista \\
\hline 01 & $\begin{array}{l}\text { Do Programa de Volta para Casa à conquista da } \\
\text { autonomia: percursos necessários para o real } \\
\text { processo de desinstitucionalização }\end{array}$ & Lima S, Brasil S & 2014 & Physis \\
\hline 02 & $\begin{array}{l}\text { Desinstitucionalização psiquiátrica: do } \\
\text { confinamento ao habitar na cidade de Belo } \\
\text { Horizonte }\end{array}$ & Franco R, Cornelis JS & 2015 & $\begin{array}{l}\text { Psicologia } \\
\& \\
\text { Sociedade } \\
\end{array}$ \\
\hline 03 & $\begin{array}{l}\text { Narrativas e sentidos do Programa de Volta para } \\
\text { Casa: voltamos e daí? }\end{array}$ & $\begin{array}{l}\text { Bessoni E, Capistrano A, Silva G, } \\
\text { Koosah J, Cruz K, Lucena M } \\
\end{array}$ & 2019 & Saúde Soc. \\
\hline 04 & $\begin{array}{l}\text { O Programa de Volta para Casa na vida } \\
\text { cotidiana dos seus beneficiários }\end{array}$ & $\begin{array}{l}\text { Guerrero A, Bessoni E, Cardoso A, } \\
\text { Vaz B, Braga-Campos F, Badaró } \\
\text { MI }\end{array}$ & 2019 & Saúde Soc. \\
\hline 05 & $\begin{array}{l}\text { Construindo histórias em tessitura lenta: } \\
\text { desinstitucionalização e narrativas em pesquisa }\end{array}$ & $\begin{array}{l}\text { Koosah J, Moreira MI, Campos- } \\
\text { Braga F }\end{array}$ & 2019 & Saúde Soc. \\
\hline
\end{tabular}

Fonte: Homepage do Scielo.

cidem com os números encontrados no sitio da Coordenação Nacional de Saúde Mental. No ano de 2017, haviam 701 municípios cadastrados no PVC e em torno de 4.499 beneficiários. O manual do programa previa em torno de 15.000 beneficiários.

As mesmas autoras ${ }^{21}$ auxiliam a reflexão sobre nossa segunda hipótese, ou seja, a ausência de relação entre o auxílio do PVC e a desinstitucionalização enquanto desconstrução. Em sua pesquisa foi constatado que o auxílio é mais voltado para suprir necessidades gerais do que para projetos de vida. Carecem, assim, estratégias para desenvolver a autonomia e empoderamento para o uso. Nesta pesquisa, também foi evidenciado que os profissionais tanto dos SRTs, como dos CAPS afirmam que faltam às redes outras estratégias para viabilizar a desinstitucionalização, como verbas e rede territorial suficiente, dificultando o uso do auxílio como instrumento para alcançar a contratualidade. As autoras destacam que a desinstitucionalização não está contida nos objetivos do PVC, não sendo encontrada nem no manual, nem na lei. Em seu lugar encontram-se "reinserção social", "inserção social", "reabilitação". Nesse sentido, cabe a pergunta: em que medida a utilização desses termos no lugar de "desinstitucionalização" despotencializa o PVC?

Chamou-nos atenção o fato de que em todas as publicações selecionadas para a nossa discussão, o PVC é normativo: elas tratam de análise sobre os efeitos da implantação do PVC nos municípios e na vida dos beneficiários. Sendo assim, observa-se uma forte influência do campo buro- crático sobre o campo científico. Um deles avalia o PVC enquanto política pública e seus impactos na vida dos beneficiários ${ }^{22}$. Neste artigo, os autores identificam a necessidade de revisão do manual do PVC e ações de orientação e capacitação de gestores para a implantação do programa e inserção de usuários; apontam para a necessidade de maior publicização das histórias dos beneficiários para demonstrar os ganhos proporcionados pelo PVC, principalmente em termos de resgate do poder de contratualidade social.

Outros estudos sobre o $\mathrm{PVC}^{23-25}$ acentuaram o caráter normativo do PVC, ao mesmo tempo em que ressaltaram sua importância como operador da desinstitucionalização. Todos esses trabalhos destacaram ambos os polos do PVC, tanto o funcional como o simbólico. O polo de dominância simbólica ultrapassa a aquisição de bens materiais e implantação de ações e serviços. Refere-se à aquisição de bens simbólicos: a contratualidade social, cuidado de si, circulação em espaços sociais, estabelecimento de relações afetivas, projeto de vida, gerenciamento do próprio dinheiro.

Assim, as narrativas mostraram no percurso da pesquisa, em um primeiro momento, a presença de um sujeito historicamente colocado à margem e que, agora, é convidado a existir e a contar-se, em um reconhecimento de si e do outro ${ }^{25}$ (p. 38).

As narrativas nos permitiram observar que o dinheiro do PVC tem sido usado para atender aos gostos e desejos pessoais dos (as) beneficiários (as), por exemplo: vestuário, produtos de higiene pessoal e beleza, tabaco, guloseimas e comidas prediletas, 
salão de beleza, aparelhos eletrônicos (celular, TV, aparelho de som), CDs, mobília, passeios e lazer em $\operatorname{geral}^{24}$ (p. 48).

Foi possível observar uma nova esfera de negociação engendrada pelo recebimento do dinheiro, colocando os beneficiários em negociação com as pessoas de seu convívio, sejam eles outros usuários, familiares ou profissionais, almejando a mudança a partir da articulação de desejos e levando em conta a própria minoridade do usuário em cada situação especifica.... ${ }^{24}$ (p. 50-51).

Podemos resumir os achados da análise dos artigos: 1) além de termos encontrado poucos trabalhos sobre o PVC, os mesmos não ressaltam o auxílio; 2) o PVC é apresentado principalmente em seu polo de dominância funcional: implantação do programa, inserção de beneficiários e as ações viabilizadas pelo programa; 3 ) o Programa contribui para a desconstrução dos estigmas da loucura: incapacidade e cronicidade. Para completar o debate aqui proposto, analisaremos a seguir como o PVC é acionado pelos atores do campo da saúde mental em eventos públicos.

\section{Eventos públicos}

Frequentamos cinco eventos no campo da saúde mental entre os anos de 2018 e 2019, identificando a maneira através da qual seus agentes acionavam o PVC nos debates (Quadro 3).

O Evento Regional Mensal do Campo Burocrático debate, com frequência, a organização de serviços extra-hospitalares para a desospitalização. Discute também a relação entre a saúde mental e o campo jurídico e algumas estratégias que contribuem com a desconstrução dos estigmas que adjetivam a loucura. Encontramos comumente a fala "é necessário que o paciente saia do hospital e viva na cidade, com garantia de educação, lazer e habitação"; "é necessário inserir este paciente na rede". Entretanto, o PVC não é abordado.

Os demais eventos, embora nacionais, possuem características distintas. A discussão sobre a saúde mental é particular em cada um deles: em sua maioria, mais voltados para a dimensão técnico-assistencial, com ênfase em processos de cuidado nos CAPS, SRTs, projetos de economia solidária e demais oficinas de inclusão social; outros são compostos por essa dimensão e duas outras, a jurídico-política e a sociocultural, com temas mais politizados de enfrentamento às desigualdades sociais, raciais, de gênero e militância no campo da saúde mental.

De um modo geral, o PVC é abordado em sua dimensão técnico-assistencial, ou em seu polo de dominância funcional, ou seja, é discutido a partir dos SRTs, que são tema de muitos trabalhos.

O Congresso Nacional Bienal do Campo Científico foi composto por minicursos, oficinas, rodas de conversa, debates, mesas redondas, intervenções artístico-culturais, como apresentações teatrais e de música. Dentre os eixos temáticos organizados pelo evento, a desinstitu-

Quadro 3. Eventos investigados para identificar a menção ao PVC.

\begin{tabular}{|l|c|l|}
\hline \multicolumn{1}{|c|}{ Evento } & Ano & \multicolumn{1}{c|}{ Participantes } \\
\hline $\begin{array}{l}\text { Evento Regional Mensal } \\
\text { do Campo Burocrático }\end{array}$ & Contínuo & $\begin{array}{l}\text { Trabalhadores da instituição promotora, eventualmente usuários, seus } \\
\text { familiares e gestão; trabalhadores da Rede de Atenção Psicossocial } \\
\text { (RAPS); graduandos, mais frequentemente dos cursos de Psicologia e } \\
\text { Direito; pesquisadores do campo da Psicologia e do Direito }\end{array}$ \\
\hline $\begin{array}{l}\text { Congresso Nacional } \\
\text { Bienal do Campo } \\
\text { Científico }\end{array}$ & 2018 & $\begin{array}{l}\text { Trabalhadores, usuários, familiares da RAPS; militantes e pesquisadores } \\
\text { do campo da saúde mental; graduandos, mais frequentemente dos cursos } \\
\text { de Psicologia, Enfermagem e Terapia Ocupacional (TO) }\end{array}$ \\
\hline $\begin{array}{l}\text { Evento Nacional Bienal } \\
\text { do Campo Científico }\end{array}$ & 2019 & $\begin{array}{l}\text { Muitos representantes de grupos sociais - indígenas, negros, } \\
\text { LGBTI+, saúde mental; Trabalhadores e usuários RAPS; graduando, } \\
\text { mais frequentemente dos cursos de Enfermagem, Psicologia e TO; } \\
\text { pesquisadores do campo da saúde mental. }\end{array}$ \\
\hline $\begin{array}{l}\text { Congresso Nacional } \\
\text { Trienal no Campo } \\
\text { Científico }\end{array}$ & 2019 & $\begin{array}{l}\text { Trabalhadores e pesquisadores do campo da Saúde Coletiva; graduandos } \\
\text { cursos do campo da saúde; representantes de grupos sociais (indígenas, } \\
\text { negros, LGBTI+, saúde mental, HIV+, entre outros) }\end{array}$ \\
\hline $\begin{array}{l}\text { Evento Regional Anual } \\
\text { do Campo Científico }\end{array}$ & 2019 & $\begin{array}{l}\text { Alunos do mestrado profissional em atenção psicossocial da instituição } \\
\text { promotora e mestres recém-formados; trabalhadores da RAPS e da Rede } \\
\text { de Saúde; pesquisadores do campo da Saúde Mental }\end{array}$ \\
\hline
\end{tabular}

Fonte: Autores. 
cionalização não estava contida. O mais próximo referia-se à clínica e integralidade de cuidados na RAPS. Haviam muitos trabalhos com o tema "desinstitucionalização", outros muitos falando sobre os SRTs, a respeito dos processos de implantação, mas nenhum diretamente sobre PVC, ou, mais especificamente, não participamos de debate que tratava do auxílio. Das apresentações que participamos, muito se falou sobre autonomia e empoderamento como operadores da desinstitucionalização, mas o PVC não foi abordado como um instrumento através do qual essas qualidades pudessem ser estimuladas.

Podemos destacar nesse evento uma exposição de fotos, em comemoração aos 15 anos do PVC. Nos banners da exposição, é enfatizado o auxílio, que juntamente com as SRTs e os CAPS constituem-se como o tripé que pauta a desinstitucionalização:

A instalação do Programa de Volta para Casa: 15 anos, concebida como jogo de espelhos com densidade histórica - imagens de 2007 a 2018 -, convida para reflexão sobre uma política de saúde mental contemporânea. A conquista da casa e da rua dos egressos do sistema psiquiátrico de Barbacena - MG, registrados em suas expressões cotidianas de contratualidade social e autonomia é reveladora dos muitos sentidos de liberdade que constroem os territórios de cidadania. (Banner de apresentação da exposição, 2018).

Em 2019, participamos do Evento Nacional Bienal do Campo Científico. Assim como o evento anterior, diversas modalidades de apresentação e debate estavam contidas: mesas-redondas e rodas de conversa. A desinstitucionalização compôs um dos eixos temáticos. Neste evento, os trabalhos apresentados foram divididos em duas categorias: relatos de pesquisa e relatos de experiência. Igualmente ao evento de 2018, muitos foram as apresentações sobre desinstitucionalização, totalizando, em ambas categorias, dezoito trabalhos. Nos relatos de experiência aparecem sete trabalhos sobre os SRTs, com apresentação de práticas de cuidado e estratégias de inclusão social. Na categoria relato de pesquisa surgiu um trabalho a respeito do PVC. Tratava-se de uma avaliação acerca das estratégias de produção de saúde no território, com egressos de internação psiquiátrica que residem em SRTs. Dentre estas estratégias foram destacados o trabalho, a autonomia, a cultura e a expressão artística, não havendo ênfase no aspecto financeiro do PVC.

O Congresso Nacional Trienal no Campo Científico, também organizou os debates em diversas modalidades. Havia dois Grupos Temáti- cos sobre saúde mental. Alguns trabalhos sobre desinstitucionalização foram apresentados, nos quais, em parte, a discussão sobre os SRTs estava presente. Entretanto, o auxílio não foi abordado. Interessante notar que muito se falou em autonomia, inclusão social e em desinstitucionalização, mas o PVC não foi mencionado.

Por fim, o Evento Regional Anual do Campo Científico organizou uma mesa sobre desinstitucionalização. Não houve apresentação de trabalho específico sobre o PVC, mas dois pontos merecem ser destacados. $\mathrm{O}$ primeiro deles se refere à definição de desinstitucionalização, caraterizada pela implantação de serviços. Dentre eles foi enfatizado os SRTs, sem menção ao auxílio. $\mathrm{O}$ segundo diz respeito à discussão sobre transinstitucionalização. Nesta discussão, a temática da moradia aparece como condição para a desinstitucionalização para muitos pacientes longamente internados. Todavia, é pautada a dificuldade de gestão para implantação e credenciamento dos SRTs. Nesse sentido, a transinstitucionalização foi colocada como uma alternativa para melhorar a qualidade de vida dessas pessoas, que não teriam outra alternativa para a desospitalização, que não os SRTs. Ademais, a mesma é afirmada como uma estratégia para a redução de leitos psiquiátricos e fechamento de clínicas psiquiátricas particulares. O pesquisador afirma " a transinstitucionalização é uma estratégia criada pra gente sobreviver, melhorar a vida de indivíduos internados".

O cenário encontrado na etnografia dos eventos nos revelou alguns dados importantes: 1) ratificou os achados da investigação do campo científico acerca do desconhecimento dos profissionais acerca do PVC como uma peça-chave para a desinstitucionalização; 2) a pouca ênfase no auxílio, ficando reduzido ao SRT; 3 ) a associação entre SRT e PVC demonstram a ênfase no polo de dominância funcional na dimensão técnico-assistencial.

\section{Considerações finais}

A desinstitucionalização envolve uma desconstrução do aparato jurídico, administrativo e médico que constrange a experiência da loucura em sintoma de doença mental ${ }^{5}$. Assim sendo, o PVC contribui para este processo, à medida que seus usuários subvertem a suposição de incapacidade e cronicidade, presentes no imaginário social da loucura. A desinstitucionalização pode ficar reduzida a um de seus sentidos, desospitalização, do mesmo modo o PVC pode se limitar a um de 
seus componentes, o SRT. Embora o auxílio seja considerado o principal componente do PVC em alguns documentos governamentais consultados, em grande parte dos documentos científicos reunidos sobre o PVC o auxílio não é mencionado. Além disso, os debates sobre o Programa em eventos do campo da saúde mental frequentados deram maior visibilidade a outro componente: $\mathrm{o}$ SRT.

A Lei 10.708/2003 institui o auxílio-reabilitação psicossocial. Do mesmo modo como a citada lei, o site do Ministério da Saúde também destaca o auxílio pecuniário como sinônimo de PVC. A cartilha sobre o PVC também posiciona o auxílio nesse lugar de destaque. Nesse sentido, é espantoso encontrar pouco ou nenhum dado sobre o auxílio nas publicações científicas acerca do PVC, mais ainda, não ouvir quase nada acerca do "principal componente" do programa quando se discute o mesmo em congressos científicos.

Entretanto, não investigamos todas as dimensões do processo de Reforma Psiquiátrica Brasileira, como é o caso da sociocultural. Não percorremos as teses, monografias e dissertações sobre o PVC, nem mesmo os capítulos de livro e coletâneas sobre o programa, de maneira que essas limitações do estudo podem ter colaborado para tal ocultamento do auxílio.

Aparentemente, a dimensão técnico-assistencial do processo de reforma psiquiátrica brasileira termina por se sobrepor à sociocultural ${ }^{1}$ inclusive quando o assunto é PVC, pois o programa acaba sendo associado às ações desenvolvidas nos SRT, mais do que ao potencial do auxílio para alterar o lugar social da loucura e assim localizar os beneficiários como capazes de gerir seus bens. Se muitas vezes o processo de Reforma Psiquiátrica Brasileira vira sinônimo de implantação de CAPS ${ }^{1}, \mathrm{o}$ PVC passa a significar principalmente expansão dos SRTs, a parte sendo tomada pelo todo, ocultando componentes relevantes para compreender as estratégias de inclusão social, que podem inclusive não passar pelo cotidiano dos serviços de saúde mental. A maioria dos estudos com beneficiários do PVC estabelece a interlocução com aqueles que se encontram nos SRTs, invisibilizando os que alugam imóveis, por exemplo, bem como o papel do auxílio nestes casos. É o polo de dominância funcional a que se referem Furtado et al..$^{12}$, por oposição ao simbólico, que termina se revelando quando registros e debates sobre o PVC ocultam o auxílio e visibilizam o SRT.

\section{Colaboradores}

MS Nascimento contribuiu para participação dos eventos estudados, elaboração do conteúdo, e análise e interpretação dos dados. MB Batista e Silva contribuiu para concepção do artigo, análise e interpretação dos dados, e revisão crítica do conteúdo. 


\section{Referências}

1. Amarante P. Teoria e crítica em saúde mental: textos selecionados. São Paulo: Zagodoni; 2015.

2. Delgado P. São João del Rei: diálogo sobre os caminhos da Reforma Psiquiátrica. Entrevista com Pedro Gabriel Delgado, em 28/06/2013. In: Melo W, Rezende P, Baeta S, organizadores. Mobilização, cidadania e participação comunitária. Rio de Janeiro: Espaço Artaud; 2016.

3. Luchmann L, Rodrigues J. O movimento antimanicomial no Brasil. Cien Saude Colet 2007; 12(2):399-407.

4. Yasui S. Rupturas e encontros: desafios da reforma psiquiátrica brasileira. Rio de Janeiro: Editora Fiocruz; 2010.

5. Rotelli F, Leonardis O, Mauri D. Desinstitucionalização, uma outra via. In: Nicácio F, organizador. Desinstitucionalização. São Paulo: Editora HUCITEC; 2001 [1990].

6. Leite L, Oliveira M, Scarparo H. Programa de Volta para Casa na cidade de Porto Alegre: fortalecimento e tessitura de vínculos no meio social. Rev Psicol Foco 2015; 7(9):3-15.

7. Silva JL, Valentim A, Lyra J. Loucura em território: experimentando produção de saúde com beneficiário do Programa de Volta para Casa. Rev Psicol Polit 2020; 20(47):51-64.

8. Venturini E. “O caminho dos cantos": morar e intersetorialidade em saúde mental. Fractal 2010; 22(3):471480.

9. Brasil. Presidência da República. Lei no 10.708 , de 31 de julho de 2003. Institui o auxílio-reabilitação psicossocial para pacientes acometidos de transtornos mentais egressos de internações, Diário Oficial de União 2003; 31 jul. [acessado 2020 jun 18]. Disponível em: http://www.planalto.gov.br/ccivil_03/Leis/2003/ L10.708.htm.

10. Brasil. Ministério da Saúde (MS). Secretaria de Atenção à Saúde. Departamento de Ações Programáticas e Estratégicas. De Volta para Casa" - Manual do Programa, s/d. Brasília: MS; 2003. [acessado 2020 jun 18]. Disponível em: http://bvsms.saude.gov.br/bvs/publicacoes/Manual_PVC.pdf.

11. Freire F, Silva VN, Oliveira M. O "Programa de Volta para Casa” no campo da saúde coletiva e saúde mental: estratégias de desinstitucionalização e reabilitação psicossocial. Catussaba 2012; 2(1):51-62.

12. Furtado J, Oda W, Borysow I, Kapp S. A concepção de território na Saúde Mental. Cad Saude Publica 2016; 32(9):1-15.

13. Vieira-da-Silva L. O campo da saúde coletiva: gênese, transformações e articulações com a reforma sanitária brasileira. Salvador, Rio de Janeiro: EDUFBA, Editora Fiocruz; 2018.

14. Azize R. Notas de um "não-prescritor": uma etnografia entre os estandes da indústria farmacêutica no Congresso Brasileiro de Psiquiatria. In: Maluf S, Torniquist C, organizadores. Gênero, saúde e aflição: abordagens antropológicas. Santa Catarina: Letras Contemporâneas; 2010.

15. Ortner S. Access: reflections on studying up in Hollywood, 2010. [cited 2019 nov 9]. Available from: https://journals.sagepub.com/doi/abs/10.1177/ 1466138110362006 .
16. Brasil. Presidência da República. Lei no 10.2016, de 06 de abril de 2001. Dispõe sobre a proteção e os direitos da pessoa portadora de transtorno mental e redireciona o modelo assistencial em saúde mental. Diário Oficial da União 2001; 6 de abril. [acessado 2020 jun 18]. Disponível em: http://www.planalto.gov.br/ccivil_03/ leis/leis_2001/110216.htm.

17. Brasil. Ministério da Saúde (MS). Secretaria de Atenção à Saúde. Legislação em saúde mental: 1990-2004. $5^{a}$ ed. ampl. Brasília: MS; 2004.

18. Venturini E. A linha curva: o espaço e o tempo da desinstitucionalização. Rio de Janeiro: Editora Fiocruz; 2016.

19. Brasil. Ministério da Saúde (MS). Secretaria Executiva. Mostra fotográfica Programa de Volta para Casa: cartilha de monitoria. Brasília: MS; 2008. [acessado 2020 jun 26]. Disponível em: https://saudementalrn. files.wordpress.com $/ 2012 / 07 /$ mostra_fotografica programa_volta_casa.pdf.

20. Brasil. Sistema Único de Saúde. Conselho Nacional de Saúde. Relatório Final da IV Conferência Nacional de Saúde Mental - Intersetorial, 27 de junho a 1 de jutho de 2010. [acessado 2020 jun 18]. Disponível em: http://conselho.saude.gov.br/biblioteca/Relatorios/ relatorio_final_IVcnsmi_cns.pdf.

21. Lima SS. Brasil SA. Do Programa de Volta para Casa à conquista da autonomia: percursos necessários para o real processo de desinstitucionalização. Physis 2014; 24(1):67-88.

22. Guerreiro AV, Bessoni EA, Cardoso AJC, Vaz BC, Braga-Campos FC. O Programa de Volta para Casa na vida cotidiana dos seus beneficiários. Saude Soc 2019; 28(3):11-20.

23. Franco RF, Cornelis JS. Desinstitucionalização psiquiátrica: do confinamento ao habitar na cidade de Belo Horizonte. Psicol Soc 2015; 27(2):312-321.

24. Bessoni E, Capistrano A, Silva G, Koosah J, Cruz K, Lucena M. Narrativas e sentidos do Programa de Volta para Casa: voltamos e daí? Saude Soc 2019; 28(3):4053.

25. Koosah J, Moreira, MIB, Braga-Campos FC. Construindo histórias em tessitura lenta: desinstitucionalização e narrativas em pesquisa. Saude Soc 2019; 28(3):29-39.

Artigo apresentado em 03/10/2020

Aprovado em 13/10/2021

Versão final apresentada em 15/10/2021

Editores-chefes: Romeu Gomes, Antônio Augusto Moura da Silva 
